\title{
Environmentally compatible hydropower potential in the estuary of the river Ems - Analysis for a floating energy converter
}

\author{
Steffi Dimke ${ }^{*}$, Frank Weichbrodt $^{1}$, Peter Froehle ${ }^{1}$ \\ ${ }^{1}$ University of Rostock, Coastal Engineering Group, Germany \\ * Corresponding author. Tel: +49 381 4983687, Fax: +49 381 4983682,E-mail: steffi.dimke@uni-rostock.de
}

\begin{abstract}
Within the EC-funded research project HYLOW - Hydropower converters for very low head differences a floating energy converter - a so called Free Stream Energy Converter (FSEC) - for the energetic utilisation of currents with slow flow velocities $(<2.0 \mathrm{~m} / \mathrm{s})$ has been developed and will be optimized until 2012 . In order to estimate the hydropower potential in case of deployment of the FSEC, a p otential analysis exemplarily for the northern part of the river Ems, at the border between Netherlands and Germany, was performed. Here, the environmentally compatible hydropower potential has a special importance. As expected, this potential is much lower than the theoretical hydropower potential. In addition to the efficiency of the energy converter, also the required water depth, existing protection areas and other uses are the main reason for the difference between the mentioned potentials in this investigation area.
\end{abstract}

Keywords: Estuary River Ems, Environmentally compatible hydropower potential, Flow velocity

\section{Nomenclature (Optional)}

$P$ theoretical power.

$\eta \quad$ efficiency factor

A flow trough area...

d water depth

$L_{\text {obstruct }}$ length of the obstructed area ..............m

$\rho$ density of water

$L_{\text {demand }}$................. length of the demanded area

$v$ flow velocity

$\mathrm{kg} / \mathrm{m}^{3}$

$n$ number of energy converter like FSEC.. -

$w_{F S E C}$ width of energy converter as FSEC..m

\section{Introduction}

According to the European Small Hydropower Association (ESHA) in European rivers an unused small hydropower resource of $5 \mathrm{GW}$ exists. An essential amount of this resource is available in terms of free stream energy with low flow velocities. The utilisation of this hydropower resource still constitutes an unsolved problem, because most current technologies are not cost effective (for low flow velocities and low discharge) and pose ecological risks to fluvial ecosystems due to blocking of the streaming water.

Within the EC-funded research project HYLOW - Hydropower converters for very low head differences a floating energy converter - a so called Free Stream Energy Converter (FSEC) for the energetic utilisation of currents with slow flow velocities $(<2.0 \mathrm{~m} / \mathrm{s})$ has been developed and will be optimized until 2012. One important objective of the investigation with the FSEC is the development of an economic hydropower converter, which minimises the well known adverse ecological effects of small hydropower devices, since the proposed technique should be able to comply with the requirements of the European Water Framework Directive.

To estimate the hydropower potential in case of the deployment of a number of FSEC's a hydropower potential analysis has been performed exemplarily for the northern part of the river Ems. One of the main objectives was the determination of the environmentally compatible hydropower potential. In the following paper, first the FSEC and the investigation area are described. After this, the results of the performed hydropower potential analysis are 
described, the estimation results of the theoretical and the environmentally compatible hydropower potential are shown.

\section{Free Stream Energy Converter}

As mentioned before, the Free Stream Energy Converter (FSEC) is a floating energy converter for the energetic utilisation of currents with slow flow velocities. It consists of a Hydraulic Pressure Wheel (HPW), which is installed between two floating bodies. The floating bodies are connected with a bottom blade (Fig. 1). The FSEC has a length of $8 \mathrm{~m}$, a width of $2.5 \mathrm{~m}$ and a draught of approx. $1 \mathrm{~m}$. The width of the HPW is $1.2 \mathrm{~m}$. This results in a flow trough area of $1.2 \mathrm{~m}^{2}$. The design velocity is about $1 \mathrm{~m} / \mathrm{s}-2 \mathrm{~m} / \mathrm{s}$. The combined effect of the HPW, the floating bodies and the bottom blade should increase the efficiency by creating a small head differences between up- and downstream of the blade. Therefore, the hydrostatic pressure difference can be used for power generation in addition to utilisation of currents. [1].

Furthermore, within the HYLOW project, the expected influences of the FSEC on the environment were theoretically assessed and are investigated in field tests. Compared to conventional technologies, the operation of FSEC is environmental friendly. For example, the $F S E C$ does not occupy the total river cross section, therefore the fauna and flora can migrate as well as sediment can be transported. As first measurements show, the water discharge and the flow conditions around the energy converter is changed only in a minor range. The FSEC also does not effect any pollution of the water. Because of that, the FSEC fits better with the ecological requirements according to the Water Framework Directive than the conventional technologies.
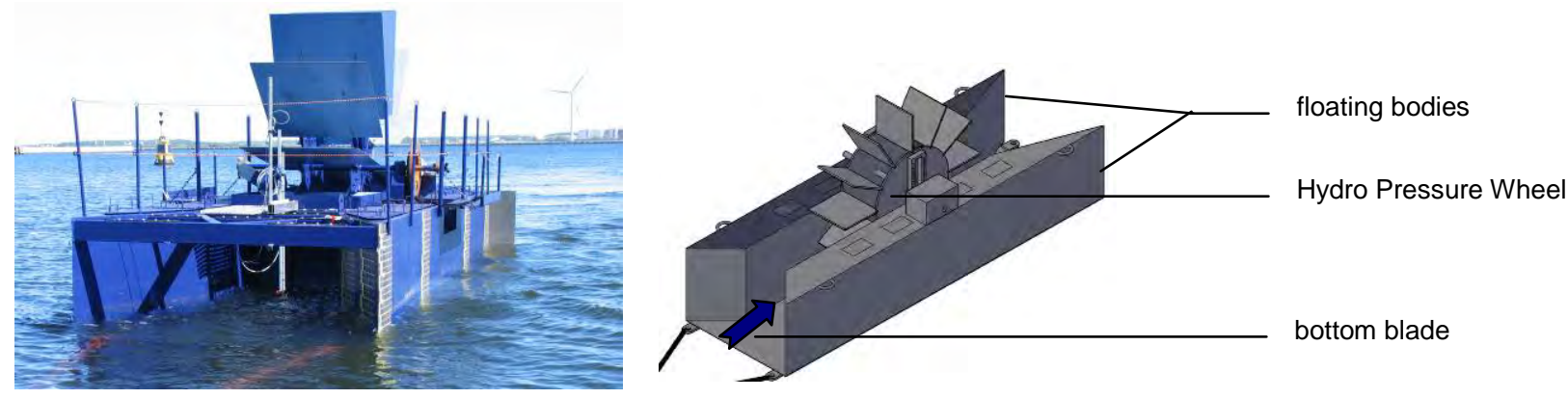

Fig. 1: Free Stream Energy Converter; length $=8 \mathrm{~m}$, width $=2.5 \mathrm{~m}$, draught $=$ approx. $1 \mathrm{~m}$

\section{Categories of small hydropower potential}

To characterize the areas for potential hydropower sites, different hydropower potentials are described. In publications different definitions for hydropower potential are available. In general the potential is divided into theoretical, technical and realistic potential. Several further sub-classifications exist.

The total availably energy is the theoretical hydropower potential, which can be calculated with following equation, (in which the efficiency factor is 1 for the theoretical potential):

$$
P=\frac{1}{2} \cdot A \cdot \rho \cdot v^{3} \cdot \eta
$$

The technical hydropower potential is only a part of the theoretical hydropower potential, which is realizable with existent techniques, at possible sites und complied with legal 
regulations. In the range between the technical and realisable hydropower potential, the environmentally complaint hydropower potential and the environmentally compatible hydropower potential can be gradated, exemplarily. The definition criteria of mentioned potentials by [2] are mentioned in Fig. 2.

For our investigation within the technical hydropower potential, efficiency of the energy converter, requirements caused by dimension and operation of the FSEC and existing water uses are considered. The protection areas are taken into account in the environmentally complaint hydropower potential. Within the environmentally complaint hydropower potential, the impacts on the environment were considered (see chapter 6).

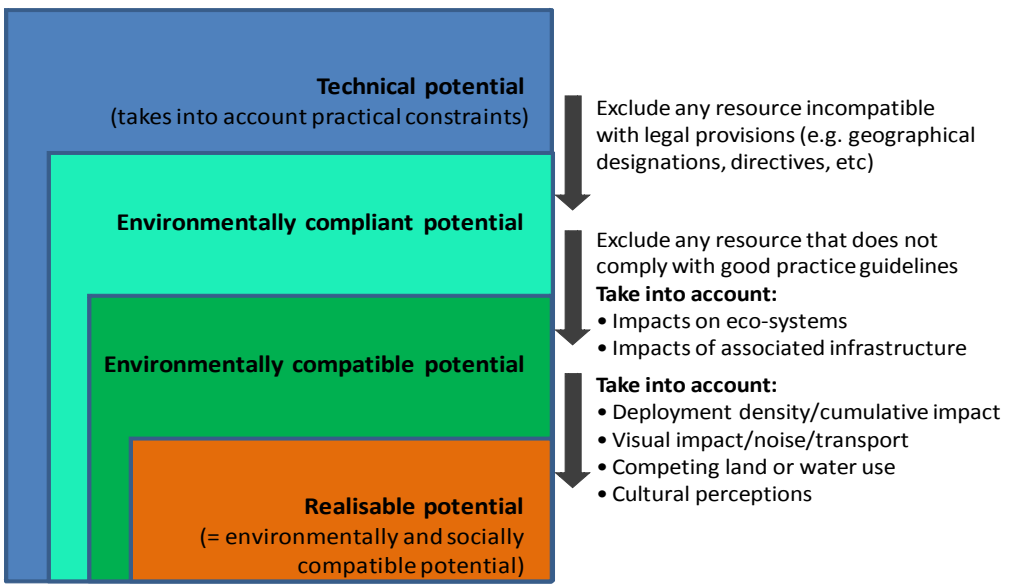

Fig. 2: Constraints to take into account when calculating the hydropower potential (after [2])

\section{Investigation area - northern part of river Ems}

\subsection{Description of the investigation area}

The investigation area is in the northern part of the river Ems, at the border between Netherlands and Germany. The river Ems has a typical river estuary which ends in the North $\mathrm{Sea}$ (Fig. 3). The river Ems is a typical European tidal river with mean tidal range of approx. $3.8 \mathrm{~m}$ and a distinctive river estuary. The average annual discharge is much higher than the average annual discharge of the river run-off, therefore not the river run-off but the discharge caused by the astronomical tide is the most important part of the total discharge and, hence, the most important factor influencing the flow velocities, too. The potential analysis for the river Ems can be stated to be exemplary for several rivers with tidal impact.

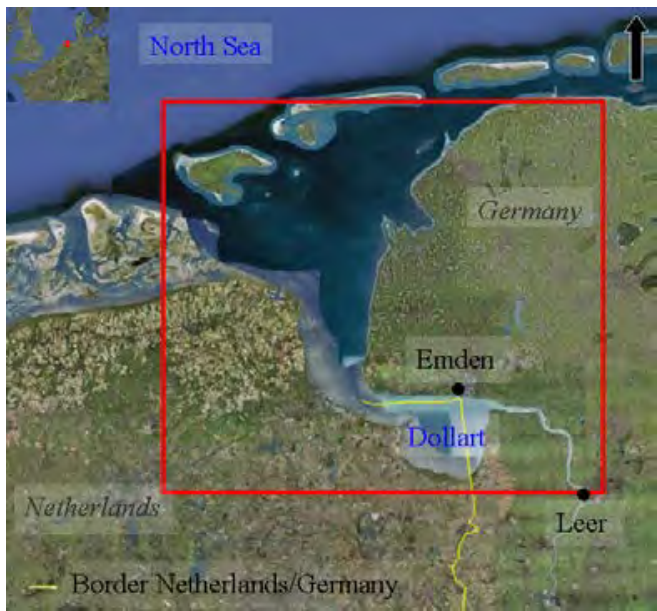

Fig. 3: Overview - investigation area (source: Google earth, modified)

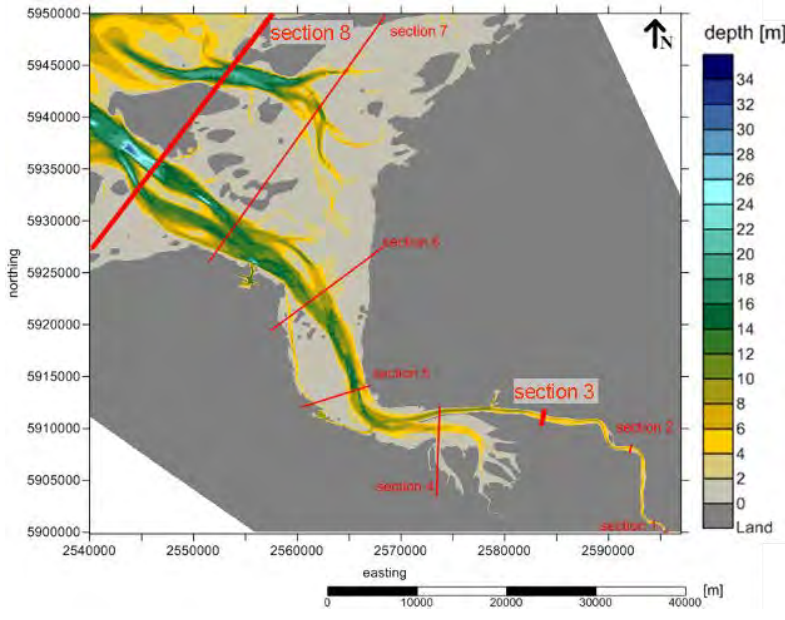

Fig. 4: sections for more detailed investigation, data source $B A W$ 
Within a detailed analysis, hydropower potentials were considered along 8 selected cross sections (see Fig. 4). Exemplarily, the investigation is described for the cross section 3 and 8 . Section 3 is a typical river section. At this section the river Ems has a maximum depth of $\mathrm{d}=7.2 \mathrm{~m}$ and a width of $\mathrm{w}=560 \mathrm{~m}$. The section 8 is typical for an estuary near the sea. The width of this section is about $\mathrm{w}=28.000 \mathrm{~m}$ and the highest depth is about $\mathrm{d}=22 \mathrm{~m}$. Section 8 crosses the border area between Netherlands and Germany and is mainly situated in a protection area, as well as section 4 to section 7 .

\subsection{Data base}

The data for the potential analysis at the Ems area is based on results of the Mathematical Model UnTRIM. The Federal Waterways Engineering and Research Institute used this numerical model to emulate and forecast the hydrodynamic conditions in the river Ems [2].

For the hydropower potential analysis the results of the simulation scenario with a constant mean run-off of $90 \mathrm{~m}^{3} / \mathrm{s}$ (average conditions) were used. The available results are representing the mean conditions of the astronomical tide and are available for approx. one day with a temporal resolution of $\Delta \mathrm{t}=10 \mathrm{~min}$ and a spatial resolution of $\Delta \mathrm{s}=$ approx. $30 \mathrm{~m} \times 30 \mathrm{~m}$. For the potential analysis the temporal resolution was reduced to $\Delta \mathrm{t}=1 \mathrm{hr}$ and a spatial resolution of $\Delta \mathrm{s}=50 \mathrm{~m}$ was used.

It can be assumed that the temporal variability of the natural flow conditions in the river, e.g. neap-spring differences, seasonally changing river run off have only negligible effects on the results of the potential analysis. Hence, the selected average conditions are extrapolated to assess the yearly potential.

\subsection{Flow velocity}

The mean tidal range is approximately $3.8 \mathrm{~m}$ and is varying along the river. The flow velocity varies with the tide and is in maximum about $2 \mathrm{~m} / \mathrm{s}$ in the whole selected investigation area. Obviously, the flow direction varies also with the tide. The tidal wave is nearly totally reflected in the investigation area which means, that between low tide and high tide, the flow is directed in the upstream direction and between high tide and low tide the flow is directed in the down-stream direction. The mean (surface) flow velocities (on basic of one day) are shown in Fig. 5. As expected, the maximum flow velocities occur in the deep flow channels of the river and, correspondingly, the flow velocities are comparatively low in the shallow water areas.

Because of the bathymetry, the tidal range at section $1 \mathrm{w}$ ith about $3.8 \mathrm{~m}$ is higher than the tidal range at section 8 . The tidal range at section 8 is about $2.75 \mathrm{~m}$. At both sections, the highest flow velocities are around $\mathrm{v}=1.6 \mathrm{~m} / \mathrm{s}$. The flow velocity curves are proportional to the water depth at both sections. Hence, the highest flow velocities are at the sites with high water depth. The mean flow velocity varies along the cross section. A cross section sites with a water depth higher than $4 \mathrm{~m}$, the mean flow velocities are about $1 \mathrm{~m} / \mathrm{s}$ in section 3 as well as in section 8 .

\section{Theoretical hydropower potential}

The theoretical potential is assessed as areal potential and based mainly on the flow velocity. The power output is determined for each grid on basis of the mean flow velocities with equation 1 . For the comparison with other results, the flow trough area is defined with $1 \mathrm{~m}^{2}$ and the efficiency factor is defined with 1 . A bi-directional converter is assumed, which is 
able to use the flow in both flow directions of the tide. In Fig. 6 the estimated theoretical hydropower potential for the investigation area is displayed. At several locations the estimated power output is higher than $1.2 \mathrm{~kW}$. For most of the areas, the estimated theoretical power is between $0.2 \mathrm{~kW}$ and $0.8 \mathrm{~kW}$.

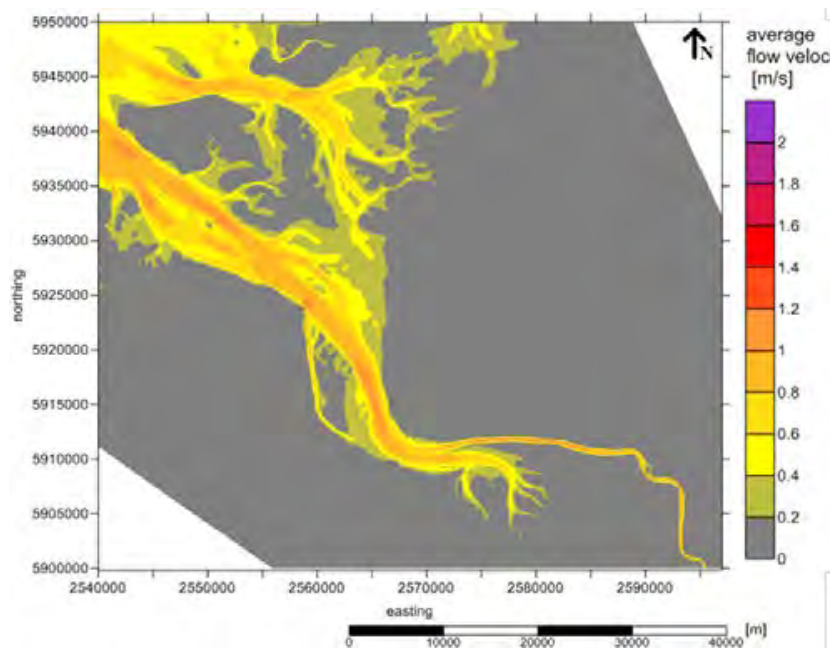

Fig. 5. average flow velocity, data source $B A W$

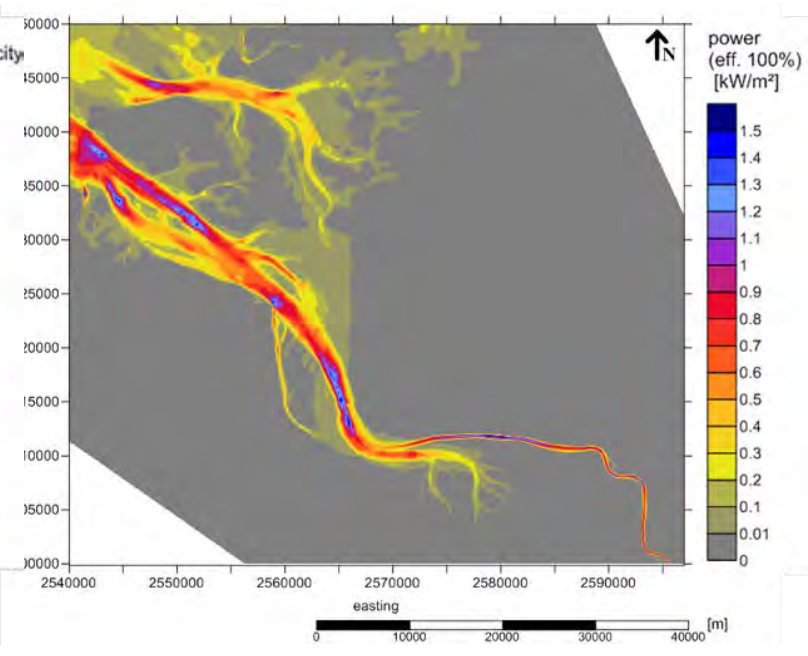

Fig. 6: theoretical power for the investigation area

An assumed realistic efficiency factor leads to decreasing estimates for the technical power. The definition of the efficiency factor for the FSEC is an objective of currently investigation and is not determined finally until now. With an assumed efficiency of $30 \%-40 \%$ the maximum power is about $0.4 \mathrm{~kW}$ to $0.5 \mathrm{~kW}$, with is in the range of the technical hydropower potential. The further factors, as water depth, other uses of the river or yearly operating hours are neglected, here. It will be considered in the following chapter.

\section{Environmentally compatible hydropower potential}

\subsection{Considered aspects}

As mentioned above, the technical hydropower potential considered the practical aspect, whether a deployment is possible regarding the technical requirements and other exiting siteuses (see chapter 3). One important aspect is the required space for the energy converter. All 8 considered cross sections are width enough to deploy a FSEC. For the FSEC (Fig. 1) the depth of the river is a restrictive factor (practical constraint). For the necessary river depth the draught of the FESC $(1 \mathrm{~m})$, the low water level and a necessary distance between river bottom and FSEC ("under keel clearance") have to be considered. The distance between bottom and $F S E C$ is necessary, to ensure the floating behaviour of the FSEC and also to ensure the pass for the aquatic fauna and sediment below the FSEC. Its minimum is defined with $1 \mathrm{~m}$. The low water level is strongly dependent on the local tidal range. The highest tidal range of the section is approx. $4 \mathrm{~m}$, in section 1 . Thus, the low water level is defined with $-2 \mathrm{~m} \mathrm{NN}$. In the sum the required average water depth is $4 \mathrm{~m}$ including all sections of the river with river beds lower than $-4 \mathrm{~m} \mathrm{NN}$.

In addition to the restrictive factor "required depth" existing uses of the river (competitive water uses) reduce the area to deploy the energy converter. In the investigation area, existing uses are mainly the use of the river as a waterway. In addition, uses like roadstead and spoil ground are of importance. The deployments of energy converter in the navigation canal are prohibited, in order to protect the navigation. A permission of hydropower deployment 
outside of the navigation canal will be decided individually under consideration of the energy converter and the chosen deployment site.

Areas which are identified by a legal restriction, e.g. protection areas, or other environmental designation will be considered by the environmentally compliant hydropower potential (see chapter 3). A large part of the investigation area is defined as natural protected area.

At the latest by the implementation of the Water Framework Directive (WFD) it is not licensable to obstruct the whole river section with anthropogenic water uses. Also within the environmentally compatible hydropower potential the impact of uses is considered (see chapter 3). As mentioned above, the operation of the FSEC has only a minor effect on the environment. As a result, the use of the environmental friendly converter, like the $F S E C$, is a contribution for the environmentally compatible hydropower potential.

It is conceivable to deploy several energy converters in some converter fields. In this case, a distance between the single energy converters is required; especially in order to provide the river continuity, which is a main objective in the WFD. For the following analysis it is assumed that uses of $25 \%$ of the river section is a minor impairment of the water bodies and therefore licensable. To not influence the operation mode and therefore the power output negatively, the distance between the single converters or to other uses and boundary are also important. Rightly this aspect is part of the technical hydropower potential.

The lateral distances between energy converters or to other uses/users or any other boundaries is chosen to 2 times of the converter width and is $5 \mathrm{~m}$. In this paper the hydropower potential is only described along cross sections, therefore, the distance between the converter in down or upstream direction is not described.

It is distinguished between the demand of area for the deployment of the FSEC and the obstructed area caused by an FSEC. The obstructed area includes only width of the FSEC. The demanded area includes over more to the width of an FSEC the required distance between two successive energy converters, to other uses or to banks. For the calculation of the obstructed areas and for the demanded area the equation (2) and (3) are used, respectively.

Obstruct area: $L_{\text {obstruct }}=n \cdot w_{F S E C}$

Demand of area for deployment: $L_{\text {demand }}=n \cdot w_{F S E C}+2 \cdot(n+1) \cdot w_{F S E C}$

In the following chapter it is determined how many energy converters like e.g. FSEC or other similar converters could be deployed along selected sections.

\subsection{Results}

The application of the mentioned aspect and the determination of the different hydropower potentials are described exemplarily along cross section 3 and 8 (see chapter 4 ). The power was determined based on the mean flow velocity and only at sites with water depths greater or equal to $4 \mathrm{~m}$. The determined power and competitive uses along section 3 and section 8 are displayed in Fig. 7 and Fig. 8.

In case of section 3, the waterway utilizes $125 \mathrm{~m}$ of the total section of approx. $560 \mathrm{~m}$. An average water depth higher than $\mathrm{d}=4 \mathrm{~m}$ is available along a $410 \mathrm{~m}$ stretch of the section. More upstream of the river Ems, almost the total cross section length with a water depth 
higher than $\mathrm{d}=4 \mathrm{~m}$ is used by the waterway (e.g. section 1), therefore a deployment of the FSEC is not possible, there. The section 8 has a length of approx. 28,000 m. Thereof, approx. $13,500 \mathrm{~m}$ are land areas, for example the island Borkum. Only along approx. 7,000 $\mathrm{m}$ of the section length the average water depth is higher than $4 \mathrm{~m}$. In addition, approx. 4,400 $\mathrm{m}$ of the remaining approx. 7,000 $\mathrm{m}$ are already in use or are protected areas. Along both sections possible deployment sites for the FSEC are remained (green lines in Fig. 7 and Fig. 8).

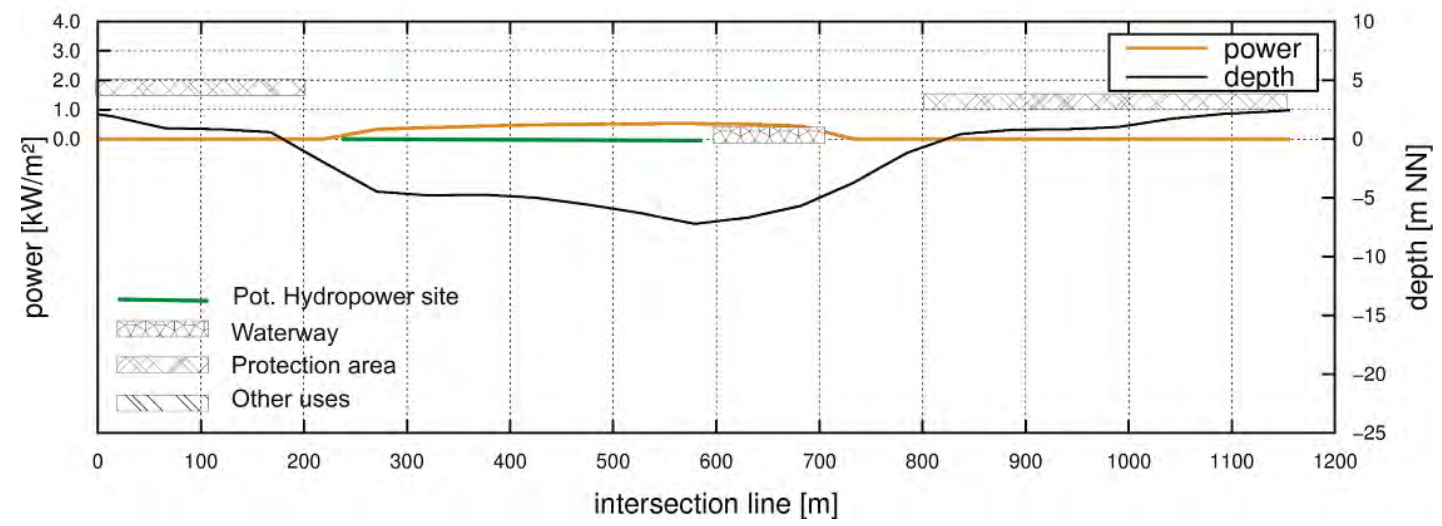

Fig. 7: Potential sites for hydropower uses and competitive uses, section 3 (power based on mean flow velocities)

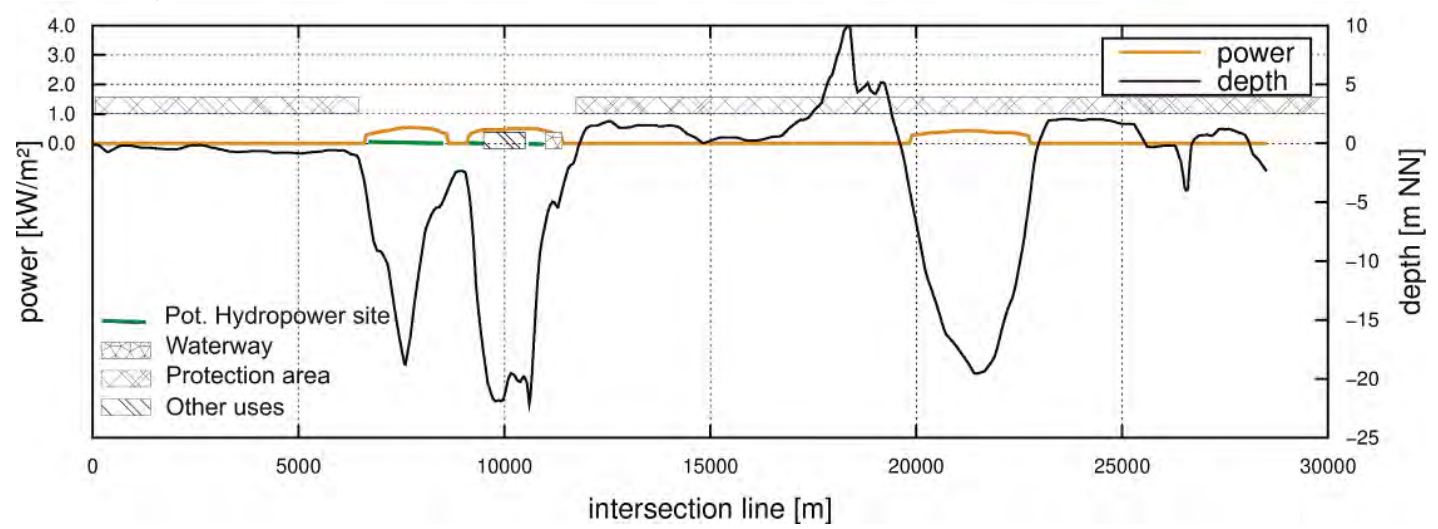

Fig. 8: Potential sites for hydropower uses and competitive uses, section 8 (power based on mean flow velocities)

Tab. 1: Properties of the sections

\begin{tabular}{|l|c|c|}
\hline & Section 1 & Section 8 \\
\hline Length of river cross section, only water areas (m) & 560 & 16,590 \\
\hline Length of river cross section with existing uses/ protections area (m) & 125 & 4,424 \\
\hline Length of river cross section d $>4 \mathrm{~m}(\mathrm{~m})$ & 411 & 7,003 \\
\hline $25 \%$ of river cross section length (m) & 141 & 4,147 \\
\hline
\end{tabular}

In Tab. 1 and Tab. 2 the properties and the environmentally compatible potential for the selected sections are presented. Along section 3 approx. $300 \mathrm{~m}$ and in the section 8 approx. $2,600 \mathrm{~m}$ could be used for the deployment of hydropower converters like the FSEC. Along all sections the obstructions of the river because of already existing uses are only minimal and therefore neglected. These results, that converter fields of possible 37 energy converters along section 3 and possible 343 energy converters along section 8 could be deployed. Accordingly, $16 \%$ of the river cross section 3 and $5 \%$ of the river cross section 8 would be obstructed.

For these possible energy converters fields the environmentally compatible hydropower potential is estimated with equation (1) on the basis of the assumptions that: all possible number of energy converter are installed, the average flow velocity $\mathrm{v}=1 \mathrm{~m}$, the flow through 
area $\mathrm{A}_{\mathrm{FSEC}}=1.2 \mathrm{~m}^{2}$ and the efficiency factor $\eta=0.3$. If all 37 energy converters along section 3 and all 343 energy converters along section 8 could be installed, the potential is estimated with $7 \mathrm{~kW}$ and $62 \mathrm{~kW}$ (see Tab. 2). The operation period depends mainly on maintenance periods and weather conditions. With a realistic 5000 ope rating hours per year, the environmentally compatible hydropower potential is estimated with $33 \mathrm{MW} / \mathrm{y}$ for section 3 and $308 \mathrm{MW} / \mathrm{y}$ for section 8 .

Tab. 2: useable resources of sections

\begin{tabular}{|l|r|r|}
\hline & Section 1 & Section 8 \\
\hline $\begin{array}{l}\text { Length of river cross section } \mathrm{d}>4 \mathrm{~m} \text { minus length of other uses/ } \\
\text { protections area }(\mathrm{m})\end{array}$ & 287 & 2,579 \\
\hline $\begin{array}{l}25 \% \text { of river cross section length minus length of other obstructing } \\
\text { uses }(\mathrm{m})\end{array}$ & 141 & 4,147 \\
\hline Possible number of energy converters & 37 & 343 \\
\hline Ratio: obstructed length / river cross section length $(\%)$ & 16 & 5 \\
\hline Potential based on $\mathrm{v}_{\mathrm{m}}=1 \mathrm{~m} / \mathrm{s}, \mathrm{A}_{\mathrm{FSEC}}=1,2 \mathrm{~m}^{2}, \eta=0.3(\mathrm{~kW})$ & 7 & 62 \\
\hline
\end{tabular}

\section{Conclusion}

The realistic hydropower potential will be lower than the afore-determined environmentally compatible hydropower potential. Furthermore the economical aspect was not considered in the paper. After the optimization procedure, the investigation costs will be calculated and put in relation with the expected power output. The estimated yearly performance per FSEC of approx. $890 \mathrm{~kW} / \mathrm{y}$ is - compared to conventional energy converters - relatively low, but the advantage of FSEC is, that it has only small influences on the environment. The river Ems is an appropriate area for the deployment of the FSEC, because energy converters could be deployed in many sites and the flow conditions are continuous over the year. For example the discharge in rivers without tidal impact is seasonally different and depends of precipitation. In several rivers the flow velocity or the water depth are too low.

\section{Acknowledgments}

The research leading to these results has received funding from the EuropeanCommunity's Seventh Framework Program [FP7/2007-2013] under grant agreement ${ }^{\circ} 212423$.

\section{References / Data sources}

[1] Mueller G. and Senior J. (2007): The hydrostatic pressure machine with free surface - a novel energy converter for very low head differences. In: Zehntes Internationales Anwenderforum Kleinwasserkraftwerke 2007, Regensburg

[2] Landy, M. (2008): A methodology to quantify the environmentally compatible potentials of selected renewable energy technologies. ETC/ACC Technical Paper 2008/16, Harwell.

[3] BAW - Waterways Engineering and Research Institute (2004). Technical Report, Mathematical Model UnTRIM, Validation Document, Version June 2004 ( 1.0), http://www.baw.de/vip/abteilungen/wbk/Methoden/hnm/untrim/PDF/vd-untrim2004.pdf.

[4] Hydrodynamic data for the river Ems: results of the "Mathematical Model UnTRIM", Federal Waterways Engineering and Research Institute 